Kumawula, Vol. 4, No.1, April 2021, Hal 1 - 7

DOI: https://doi.org/10.24198/kumawula.v4i1.29141

ISSN 2620-844X (online)

Tersedia online di http://jurnal.unpad.ac.id/kumawula/index

\title{
RANCANGAN MUTU BIOBRIKET MENGGUNAKAN TOOLS VALUE PROPOSITION CANVAS
}

\author{
Wibawa Pradana ${ }^{1}$, Dwi Purnomo², Anas Bunyamin ${ }^{3}$ \\ Program Studi Teknologi Industri Pertanian, Fakultas Teknologi Industri Pertanian, Universitas \\ Padjadjaran
}

Korespondensi : dwi.purnomo@unpad.ac.id

\begin{abstract}
Biomass briquette is one of the products that can be produced from the use of calliandra wood and tea waste. Biomass briquette made from wood and tea waste is something new, because generally biomass briquets are made from coconut shells. Market testing is needed to determine consumer response to the quality of the biomass briquette produced. The consumer response will be used to design the quality of the biomass briquette so that it can be accepted by consumers and expand the biomass briquette market. This research was conducted using the value proposition canvas tools in analyzing consumer responses to further become a reference in making biomass briquette.
\end{abstract}

Keywords: biomass briquettes; quality plan; value proposition canvas

\begin{abstract}
ABSTRAK
Biobriket menjadi salah satu produk yang dapat dihasilkan dari pemanfaatan kayu kaliandra dan limbah teh. Biobriket berbahan dasar kayu dan limbah teh ini merupakan hal baru, karena umumnya biobriket dibuat dari tempurung kelapa. Market testing diperlukan untuk mengetahui respon konsumen terhadap mutu dari biobriket yang dihasilkan. Respon konsumen nantinya digunakan untuk melakukan perancangan mutu biobriket agar dapat diterima konsumen dan memperluas pasar biobriket. Penelitian ini dilakukan menggunakan tools value proposition canvas dalam melakukan analisis respon konsumen untuk selanjutnya menjadi acuan dalam pembuatan biobriket.
\end{abstract}

Kata Kunci: biobriket; perencanaan mutu; value proposition canvas

\section{PENDAHULUAN}

Perancangan mutu sangat penting dilakukan pada produk tak terkecuali biobriket. Biobriket merupakan bahan bakar yang terbuat dari limbah bahan organik yang dipadatkan dengan menggunakan daya tekan tertentu (Zulu \& Rachmawati, 2011). Biobriket dapat menjadi salah satu energi alternatif yang ramah lingkungan, mengingat energi yang terdapat pada alam pada era globalisasi ini mulai mengalami krisis karena semakin tingginya eksploitasi. Biobriket yang akan dirancang mutunya pada penelitian ini berbahan dasar kayu kaliandra dan limbah teh.

Mutu dapat didefinisikan sebagai keadaan dinamik yang mencapai atau melebihi harapan yang diasosiasikan dengan produk, jasa, orang, proses, dan lingkungan. Keadaan dinamik yang dimaksud merujuk pada kenyataan bahwa standar "mutu" seringkali berubah sejalan dengan faktor eksternal (Goetsch, L., \& Davis, 2000).

Menurut Russel \& Taylor (1996), ada dua perspektif dalam mendefinisikan mutu, yaitu dari perspektif produser dan perspektif konsumen. Pertama, menurut perspektif 
produser mutu dikaitkan dengan standar produksi dan biaya. Hal ini berarti bahwa produk dapat dikatakan bermutu bila memenuhi kelompok konsumen. Beberapa kelompok konsumen yang dijadikan narasumber diskusi ini terdiri dari beberapa kelompok, yaitu

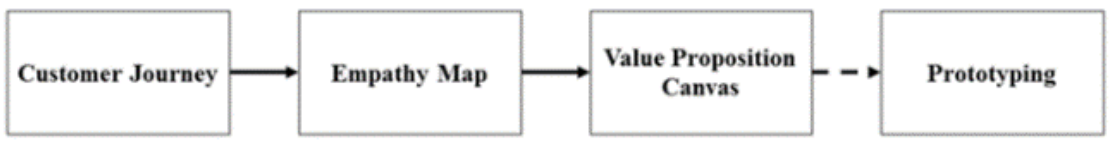

\section{Gambar 1. Tahapan Market Testing (Strategyzer)}

spesifikasi yang diinginkan dan memenuhi standar biaya produksi. Kedua, perspektif konsumen, di mana kualitas produk dilihat dari desain dan biaya. Produk yang bermutu dapat diartikan bahwa produk yang bermutu bila memenuhi karakteristik dan juga harga jual yang diinginkan.

Metode design thinking digunakan dalam menyusun perancangan mutu biobriket. Terdapat beberapa tools yang digunakan diantaranya empathy map, customer journey, dan value proposition canvas. Value yang dihasilkan nantinya akan diterapkan pada prototyping produk untuk dilakukan testing sebelum nantinya dijadikan acuan untuk standar mutu produk.

\section{METODOLOGI PENELITIAN}

Metode penelitian ini bersifat kualitatif. Metode penelitian kualitatif menurut Sugiyono (dalam Engkus, Sakti, \& Suparman, 2020) adalah metode penelitian yang berlandaskan pada filsafat positivism dan digunakan untuk meneiliti pada kondisi objek yang alamiah dengan peneliti sebagai instrument kunci penelitian. Pengumpulan data pada penelitian ini berdasarkan diskusi secara mendalam dan pengamatan langsung terhadap beberapa
UMKM, pabrik, akademisi, dan juga café. Market testing ini dilakukan untuk mengetahui perspektif konsumen terhadap mutu biobriket yang sebelumnya telah mengacu pada SNI.

\section{a. Customer Journey}

Customer journey bertujuan untuk membantu membangun peta perjalanan yang mendokumentasikan setiap proses, kebutuhan pelanggan dan interaksi sepanjang proses, serta beragam emosi yang dialami oleh pelanggan. Customer journey canvas memiliki manfaat diantaranya untuk memahami hal-hal yang dialami pelanggan dari sudut pandang mereka, untuk membangun empati pelanggan dan untuk membuat atau mendesain ulang interaksi dengan pelanggan (Stucki, 2017).

\section{b. Empathy Map}

Empathy map merupakan salah satu tools canvas yang dapat digunakan untuk membantu dalam diskusi mengenai kebutuhan konsumen. Penggunaan empathy map bertujuan untuk fokus terhadap hal yang akan diamati dan hal yang disimpulkan tentang keyakinan dan emosi kelompok konsumen yang berbeda. Empathy Map dapat mengembangkan pemahaman yang

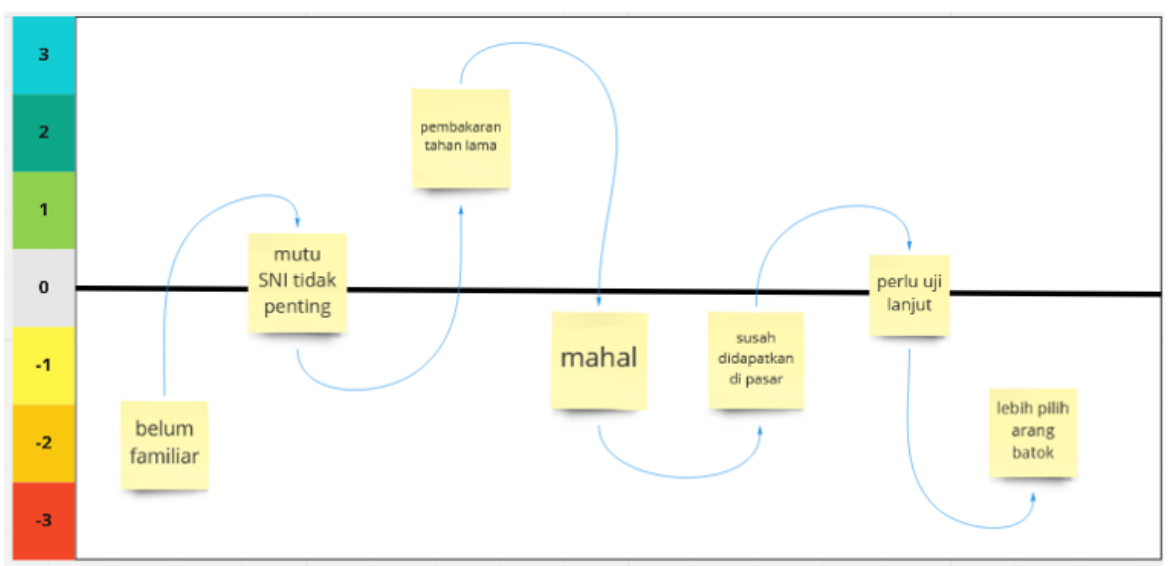

Gambar 2. Customer Journey Konsumen UMKM 
lebih baik dengan membantu mensintesis hasil observasi dan memanfaatkan pemahaman baru yang tak terduga (Gray, 2017).

\section{c. Value Proposition}

Value proposition adalah pernyataan tertulis memfokuskan semua kegiatan pasar organisasi ke elemen-elemen penting konsumen yang membuat perbedaan signifikan dalam proses pengambilan keputusan customer, untuk memilih dan/atau membeli penawaran organisasi atas pesaing (Fifield, 2007). Value propositions secara sederhana juga dikenal sebagai keunggulan dari sebuah produk yang membedakannya dengan produk dari bisnis pesaing (Fedryansyah, Pancasilawan, \& Zaenudin, 2020).

\section{HASIL DAN PEMBAHASAN}

\section{a. Customer Journey}

Tahapan pertama pada proses market testing yang dilakukan adalah diskusi secara langsung dengan para konsumen biobriket. Diskusi ini dilakukan terhadap konsumen UMKM, pabrik, akademisi, dan café. Diskusi ini dibantu menggunakan tools customer journey canvas. Hal ini untuk memudahkan dalam mengetahui beragam emosi dan juga kebutuhan konsumen.

Hasil yang didapatkan dari diskusi yang dilakukan bersama konsumen UMKM adalah bahwa masih banyak hal yang belum diterima. Hal - hal tersebut antara lain adalah belum familiarnya biobriket di kalangan
UMKM, harganya yang dianggap mahal, susah didapatkan di pasar, dan juga lebih memilih arang batok. Satu hal yang dianggap nilai lebih dari biobriket ini adalah pembakarannya dianggap lebih lama dibandingkan arang. Menurut konsumen UMKM juga mereka tidak memikirkan SNI dan perlu informasi yang lebih lengkap.

Hasil yang didapatkan dari diskusi yang dilakukan bersama konsumen pabrik adalah bahwa masih banyak hal yang belum diterima oleh konsumen pabrik. Hal - hal tersebut antara lain adalah jarang digunakannya biobriket untuk proses produksi di pabrik, keberadaannya yang dianggap unsustain, distribusi yang susah, dan residu yang banyak. Satu hal yang dianggap nilai lebih dari biobriket ini adalah pembakarannya mutu yang dihasilkan bagus. Hal lain yang didapat dalam diskusi ini adalah menurut konsumen pabrik mereka perlu melakukan investasi pada alat untuk menggunakan biobriket. Mutu yang dihasilkan juga dirasa belum spesifik.

Hasil yang didapatkan dari diskusi yang dilakukan bersama konsumen akademisi adalah bahwa masih banyak hal negatif menurut konsumen akademisi. Hal - hal tersebut antara lain adalah biobriket hanya dapat digunakan pada skala kecil, produksi biobriket di Indonesia masih rendah sehingga belum bisa digunakan secara massal dan bila dibandingkan HPPnya dengan bahan bakar lain masih kalah. Terdapat beberapa hal yang

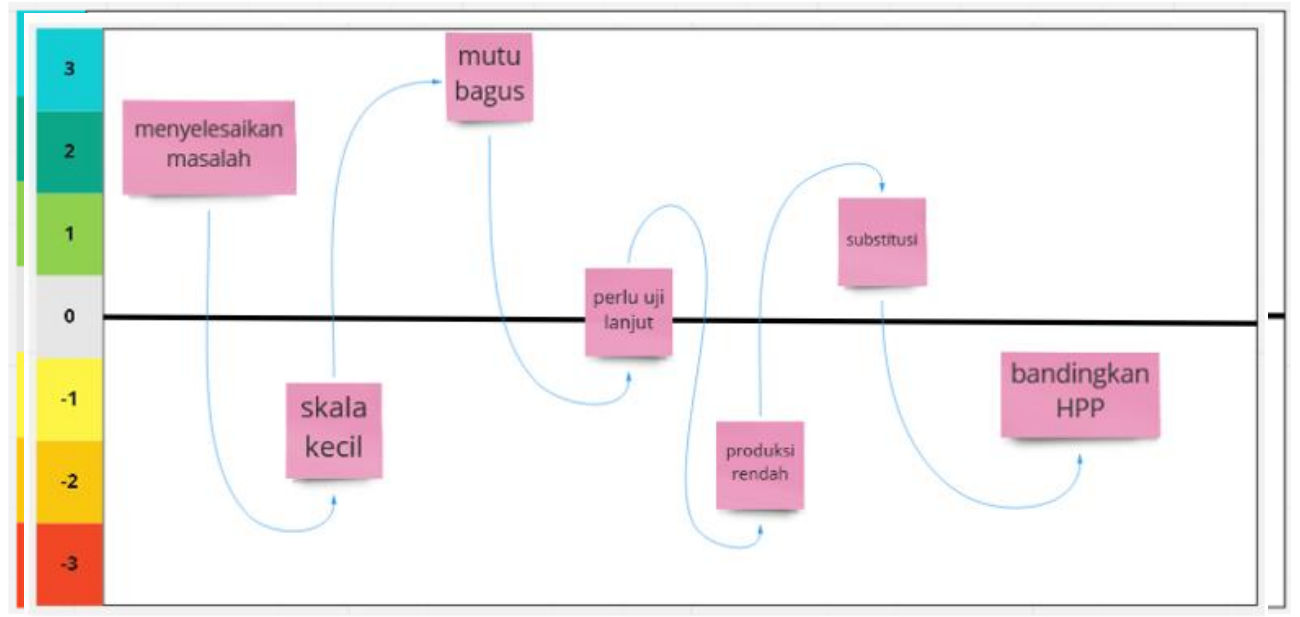

Gambar 4. Customer Journey Konsumen Akademisi 


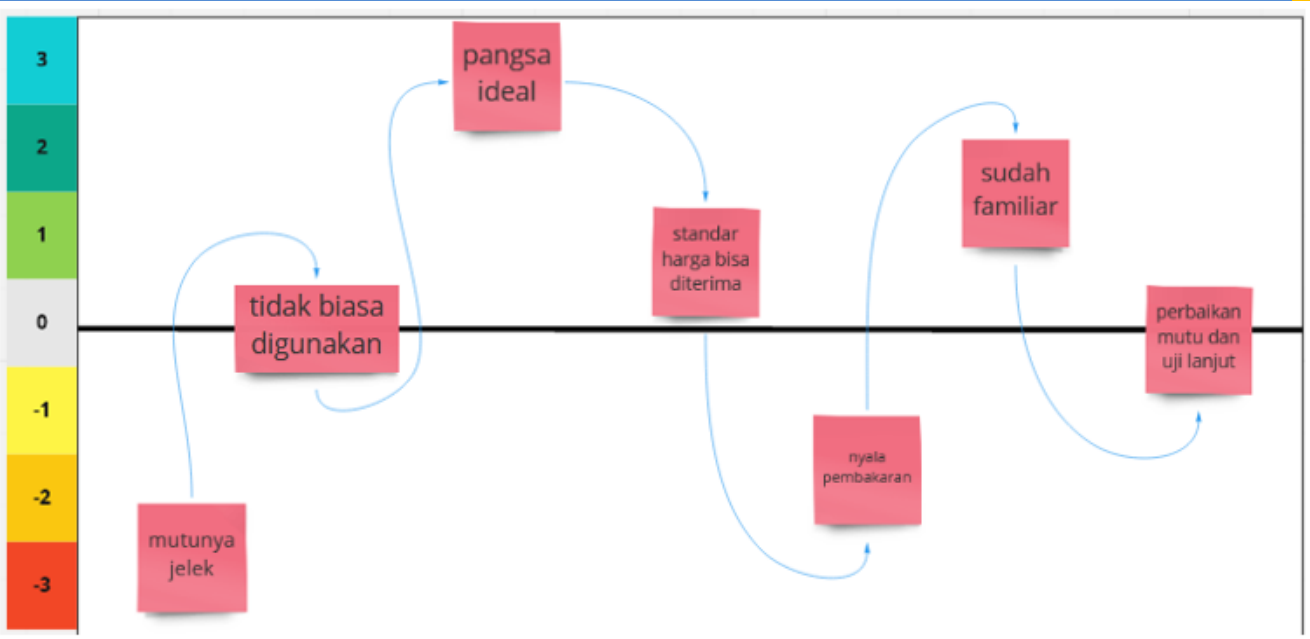

\section{Gambar 5. Customer Journey Konsumen Café}

menurut konsumen akademisi merupakan hal positif yaitu, menyelesaikan masalah limbah, biobriket yang dihasilkan bermutu bagus, dan juga dapat dijadikan substitusi bahan bakar. Hal lain yang didapatkan dari hasil diskusi bersama konsumen akademisi adalah perlu uji lanjutan baik secara mutu maupun ekonomi.

Hasil yang didapatkan dari diskusi yang dilakukan bersama konsumen café adalah bahwa ada beberapa hal negatif menurut konsumen café. Hal - hal tersebut antara lain adalah mutu biobriket yang jelek dan juga lama pembakarannya sebentar. Terdapat beberapa hal yang menurut konsumen café merupakan hal positif yaitu, pangsa pasar yang ideal, standar harga yang bisa diterima, dan juga biobriket sudah familiar digunakan untuk shisha. Hal lain yang didapatkan dari hasil diskusi bersama konsumen café adalah perlu adanya perbaikan dan uji lanjut serta biasanya konsumen cafe menggunakan biobriket dari tempurung kelapa.

\section{b. Empathy Map}

Data yang didapatkan dari hasil diskusi melalu tools customer journey kemudian dirangkum dalam empathy map untuk dibedakan berdasarkan seeing, hearing, saying, serta thinking \& feeling. Berikut merupakan empathy map yang dihasilkan:

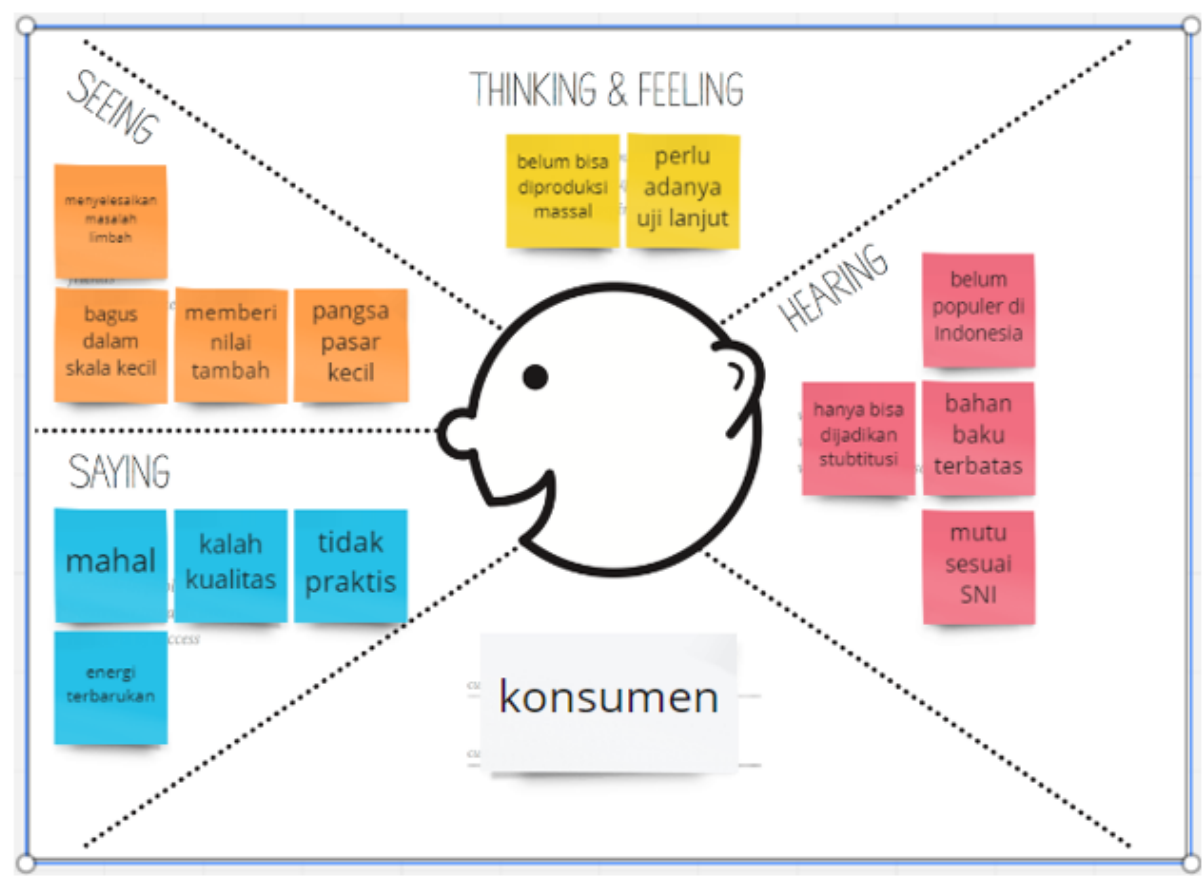

Gambar 6. Empathy Map Konsumen 


\section{- Hearing}

- Mutu sesuai SNI

Mutu biobriket yang diuji kelayakannya telah sesuai dengan SNI. Hal ini menjadi nilai positif dimata konsumen karena mutu biobriket dapat dikatakan bagus.

- Belum populer

Respon konsumen terhadap produk biobriket ini yaitu belum mengetahui apa yang dimaksud biobriket. Menurut beberapa pelaku UMKM bahkan biobriket merupakan hal yang asing dan belum umum digunakan.

- Bahan baku terbatas

Bahan baku pembuatan biobriket ini dinilai terbatas karena kayu kaliandra hanya dapat dipanen 4 kali dalam setahun dan juga limbah teh yang jumlahnya hanya dapat memenuhi kebutuhan dalam skala kecil maupun substitusi.

- Hanya bisa dijadikan substitusi

Karena ketersediaan bahan baku yang terbatas maka biobriket dari kayu kaliandra dan limbah teh ini hanya bisa dijadikan substitusi.

\section{- Seeing}

- Menyelesaikan masalah limbah

Pembuatan biobriket dari limbah teh ini tentunya juga ikut andil dalam menyelesaikan masalah limbah teh yang melimpah.

- Memberi nilai tambah

Selain menyelesaikan masalah limbah teh, pembuatan biobriket ini juga memberikan nilai tambah dan juga bernilai jual.

- Bagus dalam skala kecil

Menurut para konsumen, biobriket ini cocok diterapkan pada industri skala kecil karena mutu yang dihasilkan bagus tapi keterbatasan dalam bahan baku.

- Pangsa pasar kecil

Pangsa pasar biobriket di Indonesia masih kecil, hal ini dikarenakan biobriket dinilai kurang praktis dan juga perusahaan besar mulai beralih ke penggunaan energi listrik.

\section{- Saying}

- Energi terbarukan

Biobriket merupakan salah satu bioenergi yang merupakan sumber energi terbarukan. Penggunaan biobriket ini tidak akan berdampak buruk pada lingkungan dan juga mendukung program pemerintah terkait penggunaan energi terbarukan.

- Mahal

Harga biobriket di pasaran masih dinilai mahal oleh konsumen, hal ini dikarenakan bahan bakunya yang terbuat dari bahan alam dan juga proses pembuatannya yang cukup panjang.

- Kalah kualitas

Kualitas biobriket bila dikonversikan dengan gas ataupun listrik masih dirasa kalah oleh para konsumen. Utamanya oleh konsumen pabrik. Menurut konsumen café, kualitas biobriket dari kayu kaliandra dan limbah teh ini memiliki kualitas dibawah biobriket dari bahan baku lain seperti batok kelapa yang sudah umum digunakan.

- Tidak praktis

Penggunaan biobriket dalam industri tertentu memang perlu menggunakan alat khusus, seperti tungku pembakaran dan pengarangan dan alat lain.

\section{- Thinking and Feeling}

- Perlu uji lanjut

Perlu dilakukannya uji lanjut terkait kualitas pembakaran dan uji fisik lain untuk dapat dibandingkan dengan bahan bakar sejenis agar dapat diterima lebih baik di kalangan masyarakat

- Belum bisa diproduksi secara massal Produksi biobriket berbahan dasar kayu kaliandra dan limbah teh ini masih terbatas bahan baku, oleh karena itu baru dapat diproduksi skala kecil, dan baru bisa memenuhi permintaan industri kecil.

\section{c. Value Proposition}

Hasil analisis dari customer journey dan empapthy map yang telah didapatkan kemudian dipindahkan ke value propositions 
canvas untuk dikaji lebih lanjut hal apa saja yang perlu ditingkatkan dan diperbaiki. Berikut value propositions canvas yang dihasilkan: umum digunakan seperti arang dan juga wood pellet. Hal ini ditunjukkan dari data hasil analisis mutu SNI dimana rata - rata nilai kalor yang dihasilkan adalah sekitar $6000 \mathrm{kal} / \mathrm{gr}$.

Pains yang didapatkan dari survei ini adalah

The Value Proposition Canvas

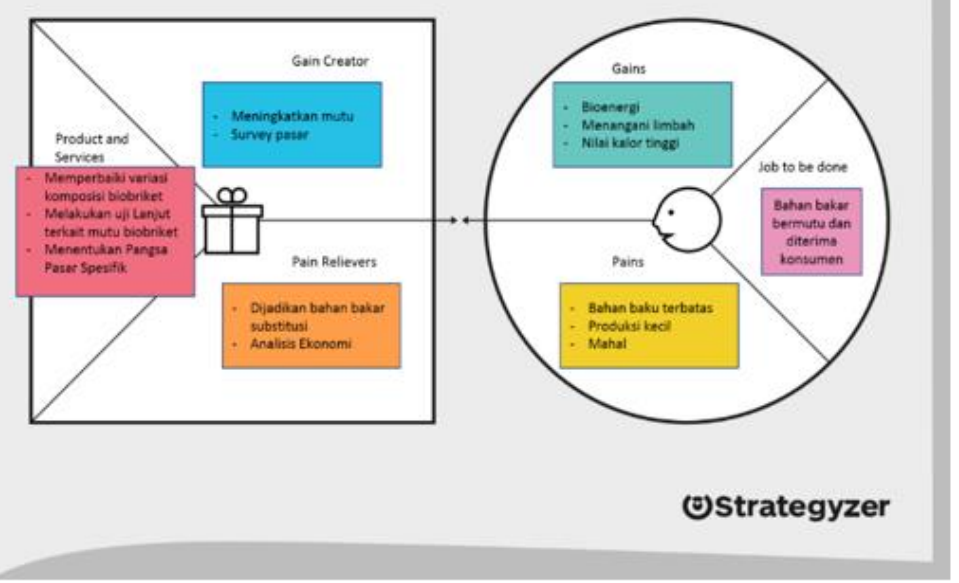

Gambar 7. Value Proposition Canvas

Job to be done dari penelitian ini adalah menghasilkan bahan bakar yang bermutu dan dapat diterima oleh masyarakat. Bahan bakar yang dijadikan sampel dalam survei yang dilakukan adalah biobriket kayu kaliandra dan juga limbah teh. Menggunakan tools value proposition canvas ini nantinya diharapkan bahwa dapat mengetahui kelebihan dan kelemahan apa saja yang terdapat pada sampel biobriket yang telah dibuat. Hal ini tentunya bisa dijadikan acuan pada peneliti untuk menguatkan kelebihan yang telah ada dan juga memperbaiki kelemahan dari biobriket ini. Melalui tools ini nantinya akan mendapatkan perbaikan seperti apa yang harus dilakukan untuk mendapatkan biobriket yang bermutu dan dapat diterima oleh masyarakat.

Gains yang didapatkan dari survei ini adalah bahwa biobriket yang dibuat oleh peneliti dapat membantu menangani limbah teh dan juga memanfaatkannya menjadi produk yang bermanfaat. Biobriket ini juga merupakan bioenergi. Hal ini sejalan dengan pemerintah yang sedang menggiatkan pemakaian energi terbarukan. Biobriket yang dibuat juga memiliki nilai kalor yang cukup tinggi bila dibandingkan dengan bahan bakar terbarukan lain yang lebih bahwa biobrket yang dibuat memiliki bahan baku yang terbatas karena menggunakan limbah teh dan juga kayu kaliandra. Limbah teh sudah tentu jumlahnya sangat terbatas karena limbah merupakan hal yang sebisa mungkin tidak dihasilkan, dan kayu kaliandra membutuhkan lahan yang sangat luas untuk produksi yang lebih massal. Hal ini membuat produksi biobriket ini hanya dapat dilakukan dalam skala kecil. Harga biobriket juga dipasaran dinilai mahal bagi beberapa kalangan.

Kelebihan atau keuntungan yang telah ada tentunya perlu ditingkatkan. Berdasarkan survei, peneliti perlu memperbaiki mutu briket untuk mendapatkan mutu yang lebih spesifik agar dapat menjangkau pangsa pasar, karena saat ini hanya mutu teknis saja yang baik, sedangkan mutu mekanis dan mutu lain yang diinginkan konsumen belum tercapai. Hal lain yang perlu ditingkatkan adalah perlu dilakukannya survei pasar yang lebih spesifik untuk lebih mengetahui pangsa pasar apa yang tepat untuk biobriket kayu kaliandra dan limbah teh ini.

Kelemahan yang dihasilkan juga perlu diperbaiki. Berdasarkan hasil survei yang dilakukan, peneliti perlu melakukan analisis ekonomi yang lebih mendalam, terkait HPP, B/C 
ratio, nilai investasi alat yang diperlukan, serta membandingkannya dengan bahan bakar lain. Hal lain yang dapat dilakukan untuk memperbaiki kelemahan yang adalah menjadikan bahan bakar ini sebagai bahan bakar substitusi, bukan menjadi bahan bakar utama apabila dibutuhkan dalam jumlah besar. Apabila ingin menjadikannya bahan bakar utama, maka harus memilih pangsa pasar yang membutuhkannya dalam jumlah sedikit.

Hasilnya perlu beberapa perbaikan terhadap biobriket kayu kaliandra dan juga limbah teh yang telah dibuat saat ini. Pertama, variasi komposisi biobriket perlu diperbaiki dan disempurnakan agar tujuan utama untuk menjadi bahan bakar terbarukan dan mengubah limbah teh menjadi produk bernilai tercapai. Kedua, perlu dilakukan uji lanjut yang lebih luas cakupannya seperti uji mekanis, analisis ekonomi, dan juga survei kebutuhan konsumen yang jelas. Terkakhir sebelum produk ini akan dipasarkan, perlu dilakukan pangsa pasar yang spesifik, karena berbeda jenis konsumen, berbeda pula mutu dan spesifikasi yang diinginkan.

\section{KESIMPULAN}

Berdasarkan hasil diskusi yang dilakukan didapatkan bahwa biobriket yang dihasilkan dapat diterima, namun belum sepenuhnya sesuai dengan mutu yang dinginkan konsumen / masyarakat. Perlu dilakukan beberapa hal untuk menjadikan biobriket dapat diterima sepenuhnya oleh masyarakat, diantaranya yaitu penghitungan HPP yang lebih dalam, dilakukannya uji mutu lanjutan untuk mendapatkan spesifikasi yang lebih jelas, dan perlu penentuan pangsa pasar yang lebih spesifik agar tepat sasaran.

\section{DAFTAR PUSTAKA}

Engkus, Sakti, F. T., \& Suparman, N. (2020). MODEL TATA KELOLA BADAN USAHA MILIK DESA (BUMDes) DI DESA LUMBUNGSARI KECAMATAN LUMBUNG KABUPATEN CIAMIS. Kumawula: Jurnal Pengabdian
Kepada Masyarakat, 3(3), 441-448. https://doi.org/https://doi.org/10.2419 8/kumawula.v3i3.28062

Fedryansyah, M., Pancasilawan, R., \& Zaenudin, $\quad$ M. (2020). PENGEMBANGAN POTENSI EKONOMI WILAYAH DALAM PERSPEKTIF KEWIRAUSAHAAN DI DESA KADAKAJAYA. Kumawula: Jurnal Pengabdian Kepada Masyarakat, 3(3), 533-538. https://doi.org/https://doi.org/10.2419 8/kumawula.v3i3.30915

Fifield, P. (2007). Marketing Strategy Masterclass :Making Marketing Strategy Happen. Butterwort Heinemann.

Goetsch, L., D., \& Davis, S. B. (2000). The Total Quality Approach to Quality Management (3rd ed). New Jersey: Prentice Hall.

Gray, D. (2017). Gamestorming.

Russel, R. S., \& Taylor, B. W. (1996). Production and Operatons Management: Focusing on Quality and Competitiveness. (III, Ed.). New Jersey: Prentice Hall Inc.

Stucki, K. (2017). The Ultimate Guide to Customer Journey Mapping.

Zulu, F. B. I., \& Rachmawati, A. (2011). PEMBUATAN BIOBRIKET DARI BLOTONG SEBAGAI BAHAN BAKAR ALTERNATIF. D3 Teknik Kimia FTI-ITS, 2923698. 